\title{
Development and validation of a simple and sensitive size-exclusion chromatography method for quantitative determination of heparin in pharmaceuticals
}

\author{
MAJA RADIVOJŠA MATANOVIĆ \\ IZTOK GRABNAR \\ PEGI AHLIN GRABNAR \\ ROBERT ROŠKAR* \\ Faculty of Pharmacy \\ University of Ljubljana \\ 1000 Ljubljana, Slovenia
}

Accepted October 23, 2014

\begin{abstract}
Heparin is widely used as an anticoagulant for the treatment and prevention of various thrombotic diseases. However, due to its high anionic charge, heterogeneity in size distribution and high polarity, its analysis is very challenging. In this paper, a novel method based on size-exclusion chromatography (SEC) for quantitative determination of intact heparin in pharmaceuticals is presented. Analyses were performed on a BioSep-SEC-S 2000 column with Larginine solution at $\mathrm{pH} 6.5$ as mobile phase and UV detection at $210 \mathrm{~nm}$. The proposed method was found to be selective, linear $\left(R^{2}>0.997\right)$ over the concentration range of 3.1 to $1222 \mu \mathrm{g} \mathrm{mL}{ }^{-1}$, with a limit of detection of $1.0 \mu \mathrm{g} \mathrm{mL}^{-1}$. Intraday and inter-day precision were below $5.1 \%$ and inaccuracy expressed as bias did not exceed $6.5 \%$. The reported method is simple, selective, sensitive, and requires no laborious sample preparation, which makes it appropriate for routine quantitative analysis of heparin in pharmaceuticals.
\end{abstract}

Keywords: heparin, quantitative analysis, size-exclusion chromatography, L-arginine

Heparin is widely used as an anticoagulant for the treatment and prevention of various thrombotic diseases. Introduced into medical practice in the 1930s, it makes one of the oldest drugs in widespread clinical use $(1,2)$. Anticoagulant activity is ascribed to a pentasaccharide moiety with a high affinity for antithrombin III (Fig. 1a). This binding results in a conformational change in antithrombin III, so that inactivation of coagulation enzymes factor IIa (thrombin), factor IXa, and factor Xa is markedly enhanced (3-5).

Heparin is a complex mixture of structurally variable unbranched glycosaminoglycans (GAGs). Polysaccharide chains are composed of 1-4 linked and variously modified L-iduronic acid and D-glucosamine repeating disaccharide subunits (Fig. 1b). High anionic charge of GAGs at physiological $\mathrm{pH}$ provides, on one hand, a non-specific water-retaining capacity essential for proper functioning of the extracellular matrix, and on the

\footnotetext{
*Correspondence; e-mail: robert.roskar@ffa.uni-lj.si
} 
other hand, the capacity to interact specifically with cationic molecules, like some proteins, through non-covalent electrostatic forces (6). Heparin is found in mast cells in a large number of mammalian and non-mammalian vertebrates, mainly in tissues that are in direct contact with the environment (i.e., lungs, skin and intestine). The molecular mass of natural (unfractionated) heparin is in the range of 5-40 kDa, although in the vast majority of preparations the $12-15 \mathrm{kDa}$ chains predominate (7). The large-scale industrial production of pharmaceutical heparin begins with its isolation, mostly from porcine intestinal mucosa (8).

a)

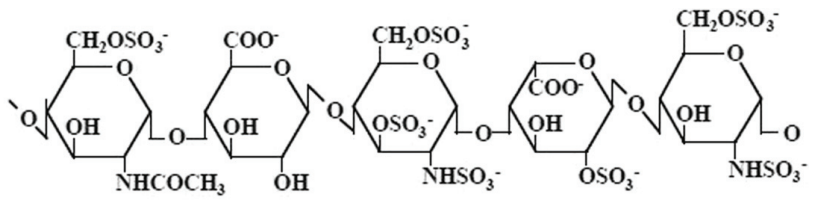

b)

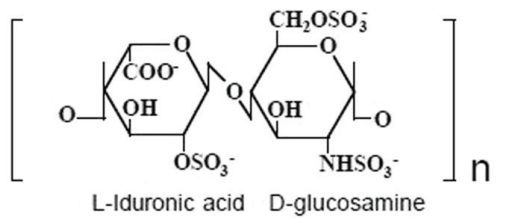

c)

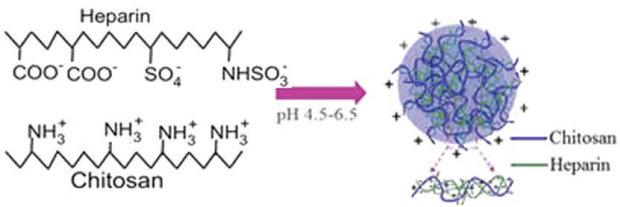

Fig. 1. Structural characteristics of heparin: a) the unique pentasaccharide binding site for antithrombin III, b) the most frequent type of disaccharide unit in a heparin molecule, c) the formation of nanocomplexes between negatively charged heparin and positively charged chitosan.

In general, most methods of GAG analysis involve a depolymerization step utilizing either enzymatic or chemical digestion of the GAG polymer chains to smaller components that are amenable to separation and structure elucidation methods. Enzymatic digestion is performed by heparin lyase enzymes from Flavobacterium heparinium, while chemical degradation involves nitrous acid or an organic nitrate. Subsequent methods for analyses of heparin derivatives include various electrophoretic and chromatographic techniques combined with fluorescence detection, mass spectrometry or nuclear magnetic resonance spectrometry $(9,10)$. Resolution of depolymerized GAGs on the basis of size can be accomplished by analytical or preparative scale size-exclusion chromatography (SEC), simplifying subsequent compositional analyses (6). SEC has also been applied for determination of molecular mass and molecular mass distribution of heparin $(6,11-15)$.

Analysis of heparin is very challenging due to its high polarity and heterogeneity in size and charge. Previously developed methods for quantitative determination of unfractionated heparin include various enzymatic bioassays (16-19) and colorimetric methods 
(20-22). To our knowledge, there is no published chromatographic method for quantitative determination of heparin other than two application notes $(23,24)$ applying strong-anionexchange liquid chromatography. According to regulations, as prescribed by the European Pharmacopoeia (18) and US Pharmacopeia (19), strong anion-exchange liquid chromatography should be used for determination of heparin related substances. Other published methods for determination of contaminants and impurities (23-27) apply the same separation principle.

We aimed to develop a simple and rapid SEC method for quantitative determination of heparin without depolymerization. Unlike other papers which used SEC for qualitative analysis of heparin $(6,11-15)$, we applied the same chromatographic approach in order to quantitatively determine heparin samples. To our knowledge, this is the first article based on measuring heparin concentrations in pharmaceuticals by SEC. The method was validated and its suitability was confirmed by analyses of commercial heparin products and an experimental heparin formulation (28).

\section{EXPERIMENTAL}

\section{Chemicals}

Heparin sodium salt analytical standard (activity $\geq 140$ USP units $\mathrm{mg}^{-1}$; 194 USP units $\mathrm{mg}^{-1}$ dry basis) was purchased from Sigma Aldrich (USA). The commercial heparin products used in this study were Heparin $\mathrm{Krka}^{\circledR} 5.000 \mathrm{IU} \mathrm{mL}^{-1}$ from Krka (Slovenia) and Heparin Braun ${ }^{\circledR} 5000 \mathrm{IU} \mathrm{mL}^{-1}$ from B. Braun Melsungen AG (Germany). Both preparations contain heparin in the form of sodium salt and are intended for intravenous or subcutaneous application. Chitosan-hydrochloride used in the nanocomplex formulation was from Kraeber\&Co $\mathrm{GmbH}$ (Germany) with a $M_{\mathrm{r}} 30-400 \mathrm{kDa}$ and degree of deacetylation of 87.2 $\%$. For preparation of various mobile phases, L-arginine, purchased from Sigma Aldrich, HPLC-grade acetonitrile, potassium dihydrogen-phosphate, sodium chloride and hydrochloric acid purchased from Merck (Germany) were used. Milli-Q water from Millipore (USA) filtered through a $0.2-\mu \mathrm{m}$ Sartorius cellulose acetate filter (Germany) was used for preparation of all mobile phases.

\section{Instrumentation and chromatographic conditions}

The HPLC system was of an Agilent LC-1200 series equipped with a quaternary pump, solvent degasser, autosampler, thermostated column compartment and UV variable detector (Agilent Technologies, USA). Chromatographic conditions are presented in Table I. Data were acquired with the Agilent ChemStation software.

\section{Standard solutions}

The stock solution of heparin $\left(1222 \mu \mathrm{g} \mathrm{mL}^{-1}\right)$ was prepared by dissolving an appropriate amount of heparin analytical standard in distilled water. Nine calibration standards in the range from 3.1 to $1222 \mu \mathrm{g} \mathrm{mL} \mathrm{m}^{-1}$ were prepared by diluting the stock solution in distilled water. Three QC samples at low $\left(9.2 \mu \mathrm{g} \mathrm{mL}^{-1}\right)$ medium $\left(92.0 \mu \mathrm{g} \mathrm{mL}^{-1}\right)$, and high $(920 \mu \mathrm{g}$ $\mathrm{mL}^{-1}$ ) heparin concentration were prepared independently on the day of analysis. QC 
M. Radivojša Matanović et al:: Development and validation of a simple and sensitive size-exclusion chromatography method for quantitative determination of heparin in pharmaceuticals, Acta Pharm. 65 (2015) 43-52.

Table I. Chromatographic conditions

\begin{tabular}{lc}
\hline HPLC system & Agilent LC-1200 \\
\hline Column & BioSep-SEC-S $2000(300 \times 7.80 \mathrm{~mm})$ \\
Mobile phase & L-arginine solution $\left(1 \mathrm{mg} \mathrm{mL}^{-1}, \mathrm{pH} 6.5\right)$ \\
Flow rate & $1 \mathrm{~mL} \mathrm{~min}^{-1}$ \\
Temperature & $40^{\circ} \mathrm{C}$ \\
Autosampler temperature & $10^{\circ} \mathrm{C}$ \\
Injection volume & $100 \mu \mathrm{L}$ \\
Detection wavelenght & $210 \mathrm{~nm}$ \\
\hline
\end{tabular}

samples and other heparin samples were also prepared by diluting the stock solution to the desired concentration using distilled water.

\section{Method validation}

The analytical method was validated according to the ICH Harmonised Tripartite Guideline for validation of analytical methods (29), evaluating the following analytical parameters: selectivity, linearity, precision, accuracy, limits of detection and quantification, and stability.

Selectivity of the method was verified by analyzing other components of the sample matrix. Chromatograms of distilled water as sample solvent and chitosan-hydrochloride (chitosan concentration was $600 \mu \mathrm{g} \mathrm{mL}^{-1}$ ) as co-excipient in the experimental heparin formulation were examined. Linearity of the method was evaluated by constructing calibration curves from nine heparin calibration standards in the range of 3.1-1222 $\mu \mathrm{g} \mathrm{mL}^{-1}$. Each calibration standard was injected twice. A calibration curve was plotted for the concentration of the drug $v s$. area and a linear least-square regression analysis was conducted to determine coefficient of determination $\left(R^{2}\right)$. The method linearity was examined on three different days. The minimally acceptable $R^{2}$ was 0.99 . The limit of detection $(D L)$ was defined as the lowest detectable heparin concentration, taking into account the standard deviation of the response $(\sigma)$ and the slope of three calibration curves $(S)$ and calculated as $D L=3.3 \mathrm{\sigma} / \mathrm{S}$. Similarly, the lower limit of quantification was calculated as $Q L=10 \mathrm{\sigma} / \mathrm{S}$. In addition, the lower limit of quantification was determined as the lowest heparin concentration on the calibration curve, estimated with a precision up to $10 \%$, as indicated by the relative standard deviation ( $R S D, \%)$, and accuracy within $\pm 10 \%$, as indicated by the relative error $(R E, \%)$. Three QC samples were prepared for the examination of accuracy on the day of analysis. The intra-day and inter-day accuracies $(n=3)$ were evaluated. The criteria for acceptable accuracy were that the mean measured QC concentrations were within \pm 10 $\%$ of nominal concentrations. Method precision was considered at the levels of intra-day and inter-day precision and expressed as RSD. Intra-day precision was calculated for each day for three replicates and the inter-day precision as RSD of the mean values was computed for three consecutive days. The acceptability of precision was set to RSD of $10 \%$. In addition, precision of the instrument was tested by injecting the same sample six times in a row. In this study, autosampler stability was evaluated by re-injection of the prepared 
sample after $24 \mathrm{~h}$ at $10^{\circ} \mathrm{C}$. The stability was then evaluated by comparing the concentration found with the nominal value.

\section{Application of the method}

Test samples were prepared by 100 -fold dilution of the commercial products Heparin $\mathrm{Krka}^{\circledR}$ and Heparin Braun ${ }^{\circledR}$ in distilled water. The samples were analyzed in three replicates by the new SEC method and by the Azure A colorimetric method (22). In brief, for the colorimetric method, equal volumes of diluted sample and Azure A aqueous solution $\left(8 \times 10^{-5} \mathrm{~mol} \mathrm{~L}^{-1}\right)$ were mixed and the absorbance was measured at $512 \mathrm{~nm}$. Furthermore, we also analyzed a heparin formulation containing heparin/chitosan nanocomplexes (28). This experimental heparin formulation was prepared by self-assembly nanocomplexation between negatively charged heparin and positively charged chitosan (Fig. 1c). The final dispersion of the nanocomplexes had a $\mathrm{pH}$ of 4.5 and nominal heparin concentration of 458 $\mu \mathrm{g} \mathrm{mL} \mathrm{m}^{-1}$. After five-fold dilution in phosphate buffer solution $\mathrm{pH}$ 7.4, the chitosan precipitated and released heparin, which was analyzed by both of the above mentioned methods.

\section{RESULTS AND DISCUSSION}

\section{Method development}

In the development of the new SEC method for quantitative determination of heparin, special attention was given to symmetry, height and tailing effect of the chromatographic peak. During method optimization, an effort was made to attain the proper mobile phase composition and convenient $\mathrm{pH}$ in order to obtain a high and narrow peak of heparin. Method development started with Milli-Q water as a mobile phase. As no signal was detected at $210 \mathrm{~nm}$, typical SEC eluents containing either $\mathrm{KH}_{2} \mathrm{PO}_{4}$ or $\mathrm{NaCl}$ salt in various concentrations $\left(50,100,200,500 \mathrm{mmol} \mathrm{L}^{-1}\right)$ were examined. The heparin peak shape was found extremely low and wide in all tested buffers (Fig. 2a). After the addition of acetonitrile as organic modifier (in proportions of 5, 10, 20,30, and 40\%, V/V) into the phosphate

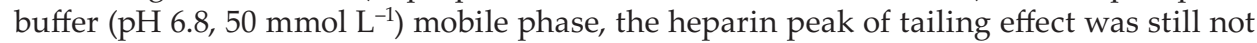
suppressed. Finally, we switched to $1 \mathrm{mg} \mathrm{mL}^{-1} \mathrm{~L}$-arginine solution ( $\left.\mathrm{pH} \sim 10\right)$, adjusted to $\mathrm{pH}$ 4.5 with $1 \mathrm{~mol} \mathrm{~L}^{-1} \mathrm{HCl}$. The heparin peak was higher and narrower, and eluted quicker, after approximately $7 \mathrm{~min}$. However, the retention time and peak shape were not reproducible even within a day. This is probably due to inadequate buffer capacity of L-arginine solution to retain the mobile phase $\mathrm{pH}$ at 4.5 during a period of several hours. Therefore, the optimal mobile phase $\mathrm{pH}$ was found to be 6.5 , which remained stable for a few days and heparin retention time was reduced to $5.5 \mathrm{~min}$ (Fig. $2 \mathrm{~b}$ ).

\section{Method validation}

Method selectivity was confirmed by the analysis of a standard, blank sample (distilled water), chitosan-hydrochloride solution, and real heparin samples. Chromatograms are given in Figs. 2b, 3a, 3b, and 3c, respectively. No interfering peak was detected in the blank sample and chitosan-hydrochloride solution at the retention time of heparin, which indicated the method selectivity. In addition, some widely used polymers and salts, in- 
M. Radivojša Matanović et al:: Development and validation of a simple and sensitive size-exclusion chromatography method for quantitative determination of heparin in pharmaceuticals, Acta Pharm. 65 (2015) 43-52.

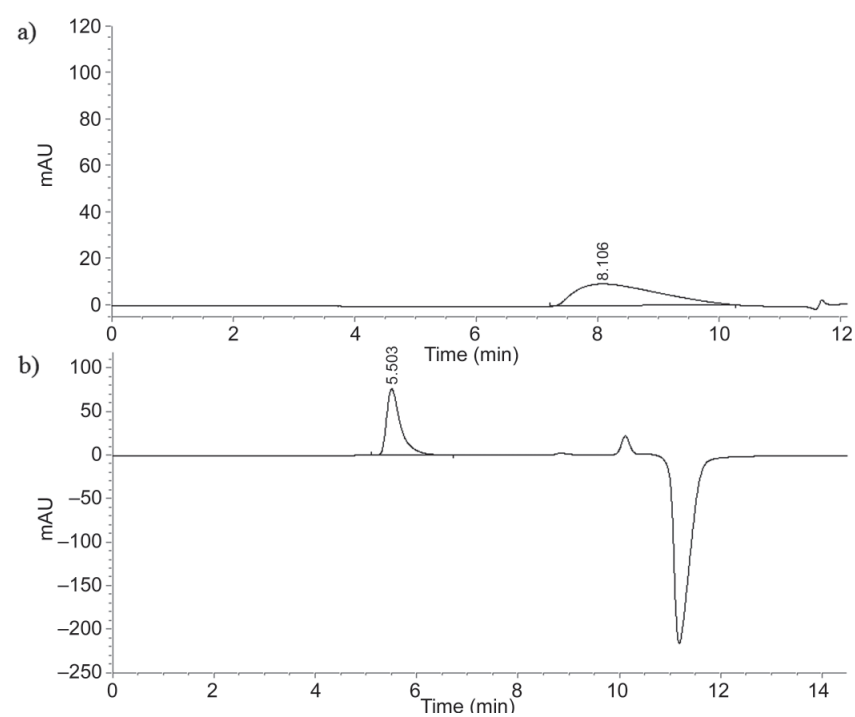

Fig. 2. SEC chromatogram of: a) standard heparin solution $\left(611 \mu \mathrm{g} \mathrm{mL} \mathrm{L}^{-1}\right)$ obtained with $\mathrm{KH}_{2} \mathrm{PO}_{4}(\mathrm{pH}$ $\left.6.8 ; 50 \mathrm{mmol} \mathrm{L}^{-1}\right)$ as a mobile phase, b) standard heparin solution $\left(306 \mu \mathrm{g} \mathrm{mL}^{-1}\right)$ obtained with L-arginine $\left(\mathrm{pH} 6.5 ; 1 \mathrm{mg} \mathrm{mL}^{-1}\right)$ as a mobile phase.

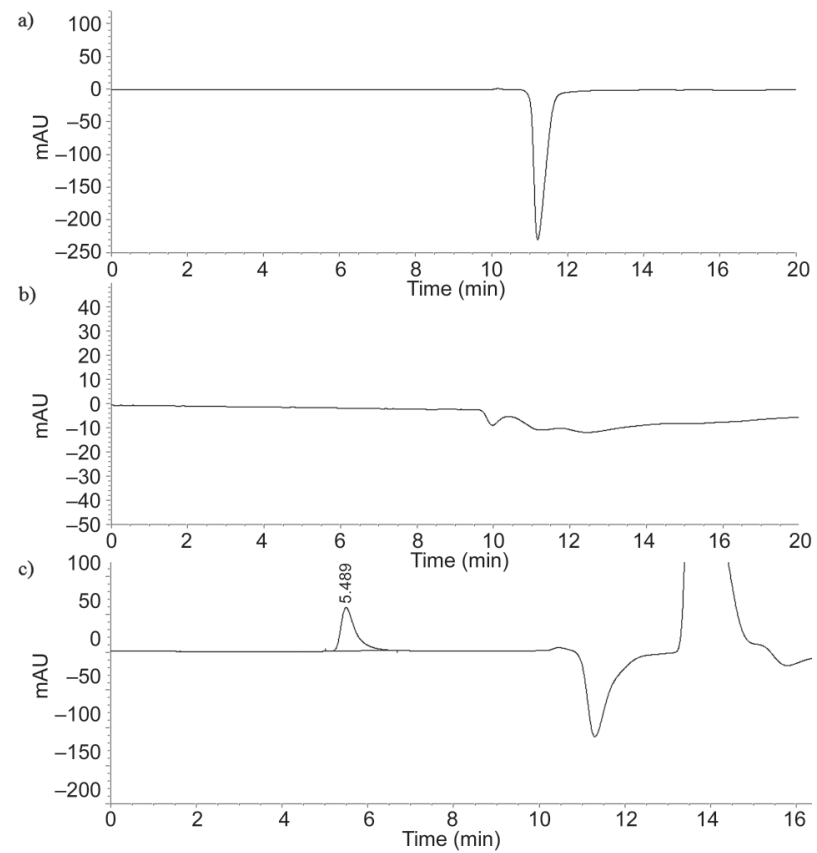

Fig. 3. SEC chromatogram of: a) distilled water as blank sample, b) chitosan-hydrochloride solution, c) commercial heparin product Heparin Braun ${ }^{\circledR}\left(306 \mu \mathrm{g} \mathrm{mL}^{-1}\right)$. 
cluding Poloxamer 407, phosphate buffer and sodium chloride, were also analyzed but no interferences were observed (data not shown).

Analytical signal was linear over the range from 3.1 to $1222 \mu \mathrm{g} \mathrm{mL} \mathrm{m}^{-1}$ with the coefficients of determination $\left(R^{2}\right)$ of $\geq 0.9971$ for three validation days. The achieved $D L$ and $Q L$ were 1.0 and $2.9 \mu \mathrm{g} \mathrm{mL}^{-1}$, respectively. According to the calibration curve, the $Q L$ was 3.1 $\mu \mathrm{g} \mathrm{mL} \mathrm{mL}^{-1}$. The presented SEC method is much more sensitive than other published chromatographic methods intended for determination of heparin related substances, which reported heparin $Q L$ of 100 and $500 \mathrm{mg} \mathrm{mL}^{-1}$ (Table II, 23, 24). The intra- and inter-day accuracy of heparin analysis ranged from -0.5 to $6.3 \%$ and -0.4 to $6.5 \%$, respectively. Table III summarizes the results for precision and accuracy. In the concentration range from 9.2 to $920 \mu \mathrm{g} \mathrm{mL} \mathrm{mL}^{-1}$, intra- and inter-day precision RSD ranged from 0.4 to $5.1 \%$ and 0.5 to 3.9 $\%$, respectively. The instrument imprecision was $1.3 \%$. Stability studies demonstrated that the sample was stable in the autosampler for at least $24 \mathrm{~h}$. The mean stability on all three QC levels was $99.2 \pm 3.0 \%$.

Table II. Quantification limits (QL) of heparin of two chromatographic methods

\begin{tabular}{lc}
\hline Method & $Q L\left(\mu \mathrm{g} \mathrm{mL} L^{-1}\right)$ \\
\hline SEC (this paper) & 3.1 \\
Ion-exchange chromatography (23) & 100 \\
Ion-exchange chromatography (24) & 500 \\
\hline
\end{tabular}

Table III. Intra- and inter-day precision and accuracy of QC samples

\begin{tabular}{cccc}
\hline & Heparin concentration nominal $\left(\mu \mathrm{g} \mathrm{mL} \mathrm{mL}^{-1}\right)$ & Inaccuracy $(\mathrm{RE}, \%)$ & Precision $(\mathrm{RSD}, \%)$ \\
\hline \multirow{4}{*}{ Intra-day } & $9.2\left(\mathrm{QC}_{\text {low }}\right)$ & 6.3 & 5.1 \\
& $92.0\left(\mathrm{QC}_{\text {medium }}\right)$ & 3.1 & 2.4 \\
& $920\left(\mathrm{QC}_{\text {high }}\right)$ & -0.5 & 0.4 \\
\hline \multirow{3}{*}{ Inter-day } & $9.2\left(\mathrm{QC}_{\text {low }}\right)$ & 6.5 & 2.2 \\
& $92.0\left(\mathrm{QC}_{\text {medium }}\right)$ & 3.7 & 3.9 \\
& $920\left(\mathrm{QC}_{\text {high }}\right)$ & -0.4 & 0.5 \\
\hline
\end{tabular}

\section{Analysis of real samples}

The chromatogram of the commercial product Heparin Braun ${ }^{\circledR}$ is presented in Fig. 3c. It demonstrates that the peak shape, resolution and retention time are comparable to that obtained using the standard heparin solution (Fig. 2b), with no interferences. Parallel results of the heparin assay of the two commercial products by the current SEC method and the literature method (22) are presented in Table IV. In both samples tested with the SEC method, heparin concentration was found slightly higher and its determination was more precise than with the Azure A method. Heparin average concentration in heparin/chitosan 
nanocomplexes (28) was found to be 93.5 and $95.3 \mu \mathrm{g} \mathrm{mL}^{-1}$ by the colorimetric and chromatographic methods, respectively. However, the results of both methods were comparable in respect to accuracy and precision, namely the differences were not significant and were in good agreement with the nominal heparin concentration. The suitability of the SEC method for quantitative determination was again confirmed.

Table IV. Heparin assay by using two methods NOVA TIV

\begin{tabular}{lccc}
\hline & $\begin{array}{c}\text { Heparin Krka } \\
(\mu \mathrm{g} \mathrm{mL})^{-1}\end{array}$ & $\begin{array}{c}\text { Heparin Braun } \\
\left(\mu \mathrm{gL}^{-1}\right)^{\mathrm{a}}\end{array}$ & $\begin{array}{c}\text { Heparin/chitosan } \\
\text { nanocomplexes } \\
\left(\mu \mathrm{g} \mathrm{mL}^{-1}\right)^{\mathrm{a}}\end{array}$ \\
\hline Size-exclusion chromatography & $307 \pm 2$ & $304 \pm 4$ & 95.3 \\
Azure A colorimetric method (22) & $303 \pm 6$ & $299 \pm 8$ & 93.5 \\
Nominal concentration & 306 & 306 & 91.6 \\
Comparison of means, $p$-value $^{\mathrm{b}}$ & 0.307 & 0.358 & - \\
Comparison of variances, $p$-value $^{\mathrm{c}}$ & 0.185 & 0.207 & - \\
\hline
\end{tabular}

a Mean $\pm \mathrm{SD}, n=3$ (only one measurement with heparin/chitosan nanocomplexes).

${ }^{\mathrm{b}}$ Independent samples $t$-test.

c Levene's test for equality of variances.

It should be mentioned that SEC is more selective compared to the colorimetric method. Even though the Azure A colorimetric method is well recognized and widely used, some limitations have been noticed in terms of selectivity. Interferences in the Azure A heparin assay were primarily observed with salts, bases and sodium dodecyl sulfate (SDS) affecting the sensitivity of the assay (30). The SEC method, however, is not affected by these interferences. This aspect is very important as various salts and SDS are frequently used as pharmaceutical excipients and buffer constituents, especially while performing typical pharmaceutical tests, e.g., the dissolution test. In spite of comparable sensitivity of both methods for quantitative heparin analysis, selectivity represents the main advantage of SEC over the Azure A colorimetric method (Table V).

Table V. Comparison of SEC and Azure A colorimetric method

\begin{tabular}{lcc}
\hline & SEC & Azure A colorimetry (22) \\
\hline Selectivity & + & - \\
Sensitivity & + & $+/-$ \\
Precision & + & + \\
Accuracy & + & + \\
Time consumption & $+/-$ & + \\
Financial costs & $+/-$ & + \\
\hline
\end{tabular}

+ is benefit; - is limitation 


\section{CONCLUSIONS}

In this study a novel, simple, selective, fast and sensitive SEC method for quantitative analysis of heparin is introduced. The method does not involve any laborious pre-analysis sample preparation. It was validated according to the ICH guidelines. The use of L-arginine solution ( $\mathrm{pH}$ 6.5, $1 \mathrm{mg} \mathrm{mL}^{-1}$ ) as a mobile phase allowed us to establish a method with a low limit of quantification because of a better shaped heparin peak. The proposed method is also precise and accurate since all parameters met the validation criteria. It was successfully applied to measure intact heparin in commercial pharmaceutical heparin products and in the experimental formulation of heparin/chitosan nanocomplexes. We believe that this method is appropriate for everyday quantitative analysis of heparin in pharmaceuticals.

\section{REFERENCES}

1. J. Hirsh, Heparin, N. Engl. J. Med. 324 (1991) 1565-1574; DOI: 10.1056/NEJM199111283252213.

2. J. Hirsh, T. E. Warkentin, S. G. Ghaughnessy, S. S. Anand, J. L. Halperin, R. Raschke, C. Granger, E. Magnus Ohman and J. E. Dalen, Heparin and low-molecular-weight heparin mechanisms of action, Pharmacokinetics, dosing, monitoring, efficacy, and safety, Chest 119 (2001) 64S-94S; DOI: 10.1378/chest.119.1_suppl.64S.

3. A. B. Blann, M. J. Landray and G. Y. H. Lip, ABC of antithrombotic therapy: An overview of antithrombotic therapy, B.M.J 325 (2002) 762-765; DOI: 10.1136/bmj.325.7367.762.

4. J. Hirsh, A. K. Bauer, M. B. Donati, M. Gould, M. M. Samama and J. I. Weitz, Parenteral anticoagulants: American College of Chest Physicians Evidence-Based Clinical Practice Guidelines (8th Ed.), Chest 133 (2008) 141S-159S; DOI: 10.1378/chest.08-0689.

5. J. Hirsh, T. E. Warkentin, R. Raschke, C. Granger, E. Magnus Ohman and J. E. Dalen, Heparin and low-molecular-weight heparin mechanisms of action, pharmacokinetics, dosing, considerations, monitoring, efficacy, and safety, Chest 114 (1998) 489S-510S; DOI: 10.1378/chest.114.5_ Supplement.489S.

6. A. Ziegler and J. Zaia, Size-exclusion chromatography of heparin oligosaccharides at high and low pressure, J. Chromatogr. B 837 (2006) 76-86; DOI: 10.1016/j.jchromb.2006.04.013.

7. S. Beni, J. F. K. Limtiaco and C. K. Larive, Analysis and characterization of heparin impurities, Anal. Bioanal. Chem. 399 (2011) 527-539; DOI: 10.1007/s00216-010-4121-x.

8. D. S. Weitz and J. I. Weitz, Update on heparin: what do we need to know?, J. Thromb. Thrombolysis 29 (2010) 199-207; DOI: 10.1007/s11239-009-0411-6.

9. A. K. Korir and C. K. Larive, Advances in the separation, sensitive detection, and characterization of heparin and heparan sulfate, Anal. Bioanal. Chem. 393 (2009) 155-169; DOI: 10.1007/s00216-0082412-2.

10. W. Mao, C. Thanawiroon and R. J. Linhardt, Capillary electrophoresis for the analysis of glycosaminoglycans and glycosaminoglycan-derived oligosaccharides, Biomed. Chromatogr. 16 (2002) 77-94; DOI: 10.1002/bmc.153.

11. J. Beirne, H. Truchan and L. Rao, Development and qualification of a size exclusion chromatography coupled with multiangle light scattering method for molecular weight determination of unfractionated heparin, Anal. Bioanal. Chem. 399 (2011) 717-725; DOI: 10.1007/s00216-010-4187-5.

12. F. Zhang, B. Yang, M. Ly, K. Solakyildirim, Z. Xiao, Z. Wang, J. M. Beaudet, A. Y. Torelli, J. S. Dordick and R. J. Linhardt, Structural characterization of heparins from different commercial sources, Anal. Bioanal. Chem. 401 (2011) 2793-2803; DOI: 10.1007/s00216-011-5367-7. 
M. Radivojša Matanović et al.: Development and validation of a simple and sensitive size-exclusion chromatography method for quantitative determination of heparin in pharmaceuticals, Acta Pharm. 65 (2015) 43-52.

13. J. E. Knobloch and P. N. Shaklee, Absolute molecular weight distribution of low-molecular-weight heparins by size-exclusion chromatography with multiangle laser light scattering detection, Anal. Biochem. 245 (1997) 231-241; DOI: 10.1006/abio.1996.9984.

14. X. Guo, M. Condra, K. Kimura, G. Berth, H. Dautzenberg and P. L. Dubin, Determination of molecular weight of heparin by size exclusion chromatography with universal calibration, Anal. Biochem. 312 (2003) 33-39; DOI: 10.1016/S0003-2697(02)00428-1.

15. S. Bertini, A. Bisio, G. Torri, D. Bensi and M. Terbojevich, Molecular weight determination of heparin and dermatan sulfate by size exclusion chromatography with a triple detector array, Biomacromolecules 6 (2005) 168-173; DOI: 10.1021/bm049693s.

16. O. F. Swoap and M. H. Kuizenga, The sheep plasma method for the bioassay of heparin preparations, J. Am. Pharm. Assoc. 38 (1949) 563-565; DOI: 10.1002/jps.3030381012.

17. C. D. Sommers, N. Montpas, A. Adam and D. A. Keire, Characterization of currently marketed heparin products: adverse event relevant bioassays, J. Pharm. Biomed. Anal. 67-68 (2012) 28-35; DOI: 10.1016/j.jpba.2012.04.017.

18. European Pharmacopoeia, $8^{\text {th }}$ ed., Vol. 2, Council of Europe, Strasbourg 2013, pp. 2390-2391.

19. United States Pharmacopoeia 36, National Formulary 31, Vol. 2, USP Convention, Rockville 2013, pp. 3801-3805.

20. P. K. Smith, A. K. Mallia and G. T. Hermanson, Colorimetric method for the assay of heparin content in immobilized heparin preparations, Anal. Biochem. 109 (1980) 466-473; DOI: 10.1016/00032697(80)90679-X.

21. I. Nemcova, P. Rychlovsky, M. Havelcova and M. Brabcova, Determination of heparin using flow injection analysis with spectrophotometric detection, Anal. Chim. Acta 401 (1999) 223-228; DOI: 10.1016/S0003-2670(99)00472-9.

22. A. Karewicz, K. Zasada, K. Szczubialka, S. Zapotoczny, R. Lach and M. Nowakowska, "Smart" alginate-hydroxypropylcellulose microbeads for controlled release of heparin, Int. J. Pharm. 385 (2010) 163-169; DOI: 10.1016/j.ijpharm.2009.10.021.

23. C. E. Doneanu and W. Chen, Impurity evaluation of heparin sodium by anion exchange chromatography, Waters Application Note, Milford (MA) 2009.

24. X. Xu, Y. Li, A. Cui and H. Chen, High Resolution Analysis of Heparin and Heparin-like Impurities on Glycomix ${ }^{T M}$ - an Anion Exchange Column. Glycan separation, Sepax Application Note, Sepax Technologies, Delaware 2012.

25. M. L. Trehy, J. C. Reepmeyer, R. E. Kolinski, B. J. Westenberger and L. F. Buhse, Analysis of heparin sodium by SAX/HPLC for contaminants and impurities, J. Pharm. Biomed. Anal. 49 (2009) 670-673; DOI: 10.1016/j.jpba.2008.12.013.

26. D. A. Keire, M. L. Trehy, J. C. Reepmeyer, R. E. Kolinski, W. Ye, J. Dunn, B. J. Westenberger and L. F. Buhse, Analysis of crude heparin by ${ }^{1} \mathrm{H}$ NMR, capillary electrophoresis, and strong-anion-exchange-HPLC for contamination by over sulfated chondroitin sulfate, J. Pharm. Biomed. Anal. 51 (2010) 921-926; DOI: 10.1016/j.jpba.2009.10.017.

27. D. A. Keire, D. J. Mans, H. Ye, R. E. Kolinski and L. F. Buhse, Assay of possible economically motivated additives or native impurities levels in heparin by ${ }^{1} \mathrm{H}$ NMR, SAX-HPLC, and anticoagulation time approaches, J. Pharm. Biomed. Anal. 52 (2010) 656-664; DOI: 10.1016/j.jpba.2010.02.019.

28. M. Radivojša, I. Grabnar and P. Ahlin Grabnar, Thermoreversible in situ gelling poloxamer-based systems with chitosan nanocomplexes for prolonged subcutaneous delivery of heparin: Design and in vitro evaluation, Eur. J. Pharm. Sci. 50 (2013) 93-101; DOI: 10.1016/j.ejps.2013.03.002.

29. International Conference on Harmonisation of Technical Requirements for Registration of Pharmaceuticals for Human Use, ICH Harmonized Tripartite Guideline, Validation of Analytical Procedures: Text and Methodology Q2(R1), Current Step 4 version, Geneva, November 2005.

30. Q. Jiao and Q. Liu, Mechanism of interference and Azur A response in the heparin assay, Anal. Lett. 31 (1998) 1311-1323; DOI: 10.1080/00032719808002868. 